\title{
Effect of Heated Humidification on CPAP Therapy Adherence in Subjects With Obstructive Sleep Apnea With Nasopharyngeal Symptoms
}

\author{
Chuleekorn Soudorn MD, Dittapol Muntham, Sirimon Reutrakul MD, and \\ Naricha Chirakalwasan MD
}

\begin{abstract}
BACKGROUND: The addition of heated humidification to CPAP has been shown to improve nasal adverse effects in subjects with obstructive sleep apnea (OSA). However, current data regarding improvement in CPAP adherence is conflicting. Furthermore, there are no data from a tropical climate area with a high humidity level. METHODS: In this prospective randomized crossover study conducted in Thailand, subjects with moderate to severe OSA with nasopharyngeal symptoms post-split-night study were enrolled in the study. Subjects were randomly assigned to receive CPAP with or without heated humidification for 4 weeks and then crossed over. Information on CPAP adherence, quality of life assessed by the Functional Outcomes of Sleep Questionnaire, nasopharyngeal symptoms assessed by a modified XERO questionnaire, and bedroom ambient humidity and temperature data were obtained. RESULTS: Data were collected on 20 subjects with OSA during the period of January to December 2014. Although the addition of heated humidification appeared to improve average hours of use for all days when compared with conventional CPAP, the difference was not statistically significant (CPAP with heated humidification $=4.6 \pm 1.7 \mathrm{~h} / \mathrm{night}$; conventional CPAP $=4.0 \pm 1.7 \mathrm{~h} / \mathrm{night}, P=.1)$. However, the addition of heated humidification improved CPAP adherence on the days of use $(5.5 \pm 1.5 \mathrm{~h} / \mathrm{night})$ compared with conventional CPAP (5.2 $\pm 1.4 \mathrm{~h} / \mathrm{night}), P=.033$. Quality of life was also improved according to the Functional Outcomes of Sleep Questionnaire score (median 17.6 [interquartile range 3.5]) in the heated humidification group compared with conventional CPAP group (median 17.6 [interquartile range 4.5]), $P=.046$. Significant reduction in the dry throat/sore throat symptom was noted only when CPAP with heated humidification was used. CONCLUSIONS: Even in a tropical climate area, CPAP adherence and quality of life appeared to improve when heated humidification was employed in subjects with moderate to severe OSA with nasopharyngeal symptoms post-split-night polysomnography. The improvement may be related to a reduction in the dry throat/sore throat symptom. Key words: obstructive sleep apnea; CPAP; adherence; heated humidification; quality of life. [Respir Care 2016;61(9):1151-1159. (c) 2016 Daedalus Enterprises]
\end{abstract}

\section{Introduction}

CPAP has been used as a standard therapy for moderate to severe obstructive sleep apnea (OSA). ${ }^{1}$ However, un-

\footnotetext{
Drs Soudorn and Chirakalwasan are affiliated with the Division of Pulmonary and Critical Care Medicine, Department of Medicine, Faculty of Medicine, Chulalongkorn University and the Excellence Center for Sleep Disorders, King Chulalongkorn Memorial Hospital, Thai Red Cross Society, Bangkok, Thailand. Dr Muntham is affiliated with the Excellence Center for Sleep Disorders, King Chulalongkorn Memorial Hospital, Thai Red Cross Society, Bangkok, Thailand and the Section for Mathematics, Faculty of Science and Technology, Rajamangala University of Technology Suvarnabhumi, Phranakhon Si Ayutthaya, Thailand. Dr Re-
}

desirable nasal and oral adverse effects have been frequently described in patients using CPAP. ${ }^{2}$ The discomfort caused by breathing only through the nasal route,

\footnotetext{
utrakul is affiliated with the Section of Endocrinology and Metabolism, Department of Medicine, Faculty of Medicine Ramathibodi Hospital, Mahidol University, Bangkok, Thailand.

This work was supported by the Ratchadaphiseksomphot Endowment Fund of Chulalongkorn University. All CPAP machines and related equipment were sponsored by Fisher and Paykel Healthcare Limited. However, the company had no impact on study design or interpretation of the results of the study. SR has disclosed relationships with Sanofi, Medtronic, and Merck. The other authors have disclosed no conflicts of interest.
} 


\section{EFFect of Heated Humidification on CPAP AdHERENCE IN OSA}

particularly in patients with chronic nasal symptoms, reported by up to $20 \%$ of OSA patients, can lead to CPAP refusal. ${ }^{3}$ Although several mechanisms may possibly be involved in the development of nasal discomfort, mouth leaks during the use of CPAP seem to be particularly important because they can cause unidirectional inspiratory nasal air flow and progressive drying of the nasal mucosa. This mechanism is also known to promote the release of inflammatory mediators, which leads to an increase in nasal airway resistance. ${ }^{3}$

Generally, CPAP adherence has been reported ranging from 40 to $78 \% .^{2}$ Thus, an intervention designed to improve adherence might be of benefit if introduced when treatment is initiated. Improved adherence with CPAP might also lead to greater improvements in quality of life. ${ }^{1}$

Mador et $\mathrm{al}^{4}$ have shown that CPAP with heated humidification compared with CPAP alone significantly improved adverse effects related to CPAP use, including dry nose, dry mouth, and dry throat. However, there was no difference in adherence. Rakotonanahary et $\mathrm{al}^{5}$ conducted a prospective cohort study on subjects with OSA who developed upper airway symptoms leading to utilization of a cold humidifier and subsequently a heated humidifier if symptoms persisted. Their study demonstrated that the heated humidifier but not the cold humidifier significantly improved CPAP adherence. ${ }^{5}$ Massie et $\mathrm{al}^{6}$ conducted a randomized, crossover design using CPAP with heated humidity and CPAP with cold passover humidity. Each treatment was applied for 3 weeks with a 2-week washout period. This study reported results similar to those of the study by Rakotonanahary et al. ${ }^{5}$ Heated humidity, but not the cold passover humidity, significantly improved CPAP adherence. Dry mouth or throat and dry nose were reported less frequently when CPAP was used with heated humidity compared with CPAP use without humidity. ${ }^{6}$ More recent studies did not show the positive effects of heated humidification on adherence when heated humidification was used routinely; however, nasal symptoms were significantly improved..$^{7-9}$ The discrepancy of the results warrants further studies.

The objectives of our research were to study the effects of heated humidification on CPAP adherence, nasopha-

Dr Soudorn presented a version of this work at the Annual Meeting of The Royal College of Physicians of Thailand, held March 26-29, 2015 at Bangkok Convention Centara at Central World in Bangkok, Thailand.

Correspondence: Naricha Chirakalwasan MD, Division of Pulmonary and Critical Care Medicine, Department of Medicine, Faculty of Medicine, Chulalongkorn University, Medicine, Chulalongkorn University, 1873 Rama IV Road, Pathumwan, Bangkok, Thailand 10330. E-mail: narichac@hotmail.com.

DOI: $10.4187 /$ respcare.04536

\section{QUICK LOOK}

\section{Current knowledge}

Despite CPAP being the main treatment for obstructive sleep apnea (OSA), poor adherence remains the major problem compromising its treatment. Current data on the effect of the addition of heated humidification on CPAP adherence are conflicting. Furthermore, there are no data from the tropical climate area with an already high humidity level.

\section{What this paper contributes to our knowledge}

The addition of heated humidification appeared to improve CPAP adherence and quality of life when it was employed in subjects with OSA with nasopharyngeal symptoms documented post-split-night polysomnography. The ambient humidity level did not seem to have an effect on CPAP adherence.

ryngeal symptoms, quality of life, and subjective sleepiness when heated humidification was applied to CPAP in subjects with OSA who reported nasopharyngeal symptoms from CPAP titration during a split-night sleep study. We hypothesized that only subjects with significant upper airway symptoms would benefit from heated humidification, particularly if it is to be applied early. Furthermore, there are no data from a tropical climate area with a higher relative humidity level, which may have an effect on the benefit of heated humidification.

\section{Methods}

\section{Subjects}

Patients referred to the sleep clinic at King Chulalongkorn Memorial Hospital age $>18$ y with a diagnosis of moderate to severe OSA (apnea-hypopnea index $[\mathrm{AHI}] \geq$ 15) based on split-night polysomnography were screened for the study. After CPAP titration, patients completed a post-test questionnaire using a modified XERO questionnaire, ${ }^{10}$ which addressed nasopharyngeal symptoms. If the score of any of the nasopharyngeal symptoms was $>2$ (moderate symptom), patients were offered participation in the study. Exclusion criteria were as follows: $>5$ central apneas/h of sleep, acute infection, heart failure with New York Heart Association classification 3 or 4, acute pulmonary embolism, acute coronary syndrome, travel plans outside of Thailand within 2 months of the study, baseline pattern of split-night polysomnography $<2 \mathrm{~h}$, less than optimal CPAP titration, and the use of humidification during the split-night study. The Chulalongkorn University 


\section{EFFect of Heated Humidification on CPAP AdHERENCE IN OSA}

ethics committee approved the study, and all subjects gave their written informed consent registered on the Thai Clinical Trials Registry (http://www.clinicaltrials.in.th/ [TCTR20140106003]).

\section{Questionnaires}

All participants were asked to complete a set of questionnaires at baseline, after 4 weeks, and after 8 weeks of treatment. Quality of life was assessed using the Functional Outcomes of Sleep Questionnaire, which consists of 30 items focusing on 5 domains, including general productivity, social outcome, activity level, vigilance, and intimate relationships and sexual activity. A response score of 0 for an item means that the activity was not done for other reasons. A score response of 1-4 indicates the difficulty level in performing each activity, where a lower score indicates more difficulty. The potential range of scores for the total score is 5-20. Subjective sleepiness was evaluated with the Epworth Sleepiness Scale. The Epworth Sleepiness Scale is a set of questions that ask how likely a person is to fall asleep in 8 different situations. Each question was answered on a scale of $0-3$. Epworth Sleepiness Scale values ranged from 0 (unlikely to fall asleep in any situation) to 24 (high chance of falling sleep in all 8 situations). Epworth Sleepiness Scale values of $\geq 10$ usually indicate excessive daytime sleepiness. Both questionnaires were validated in the Thai language. ${ }^{11,12}$ Nasopharyngeal adverse effects were assessed by using a modified XERO questionnaire, which included the symptoms of blocked nose, dry nose, runny nose, dry mouth, dry throat/sore throat, itchy eyes, and watery eyes. Each question was scored on a 5 -point scale $(0=$ no symptom, $5=$ very severe symptom). All questionnaires were self-administered forms with assistance, if needed, provided by an investigator.

\section{Polysomnography}

All split-night polysomnography was conducted in the sleep laboratory using standard electroencephalography, including frontal leads (F1, F2), central leads (C3, C4), occipital leads $(\mathrm{O} 1, \mathrm{O} 2)$, reference leads at mastoids (M1, $\mathrm{M} 2$ ), electromyography, and electrooculography. $\mathrm{S}_{\mathrm{pO}_{2}}$ was measured with a finger probe. Air flow was measured by 2 methods: a nasal pressure transducer and an oral-nasal thermocouple. The thoracic and abdominal respiratory movements were monitored by respiratory inductance plethysmography. The body position was measured by a position sensor, which was attached to the anterior chest wall on the thoracic belt. The sensor differentiated 5 positions, including supine and non-supine positions (right, left, prone, and upright positions). Sleep stages were scored in 30-s epochs according to the standard criteria from the
American Academy of Sleep Medicine manual. ${ }^{13}$ Apnea was defined using oral-nasal thermocouple excursion, and hypopnea was defined using nasal pressure transducer excursion. Apnea, hypopnea, and respiratory effort-related arousals were scored using the standard criteria from the American Academy of Sleep Medicine manual. ${ }^{13}$ The number of apneas and hypopneas per total sleep time were calculated and reported as the AHI. The number of apneas, hypopneas, and respiratory effort-related arousals per total sleep time was calculated and reported as the respiratory disturbance index. Parameters of oxygenation included in the study were absolute nadir oxygen saturation during sleep, mean oxygen saturation during sleep, and percentage of sleep time spent with oxygen saturation $<90 \%$. Arousal per total sleep time was reported as the arousal index. Sleep efficiency was defined as a ratio of total sleep time over the total recording time in percentage. Time spent in NREM1, NREM2, NREM3, and REM was calculated as a percentage of the total sleep time. The splitnight study was conducted according to standard guidelines using the criteria of $\mathrm{AHI} \geq 40$ events/h during the first $2 \mathrm{~h}$ or AHI of $20-40$ events/h if there was significant oxygen desaturation. ${ }^{14}$ During CPAP titration, a pressure signal from the mask was recorded. This signal was used to score the respiratory events in replacement of the nasal pressure transducer and the oral-nasal thermocouple. A CPAP titration was performed under a standard protocol. ${ }^{15}$ We only enrolled subjects who achieved optimal CPAP titration, defined by a titration that reaches the pressure that reduces the respiratory disturbance index to $<5$ events/h for $\geq 15$-min duration and included supine REM sleep that was not interrupted by spontaneous arousals or awakenings. ${ }^{15}$

\section{CPAP Device}

The CPAP device utilized for home treatment was a fixed-pressure CPAP device: the ICON Premo (Fisher \& Paykel Healthcare, Auckland, New Zealand) with ThermoSmart technology. This CPAP machine has a unique feature with the built-in heated humidification system. It also has a heated circuit, which reduces condensation. During the period when the subjects were assigned to use CPAP with heated humidification, the humidity setting was turned on and set at level 4 with a heated circuit boost setting at level 2. This setting was based on the manufacturer's standard recommendation. No adjustment of the humidification setting was allowed during the study. During the period when the subjects were assigned to use CPAP without heated humidification, the heated humidification was inactivated. The subjects were instructed to refill the water in the humidifier chamber every time before each CPAP use both during the use of CPAP with humidification and during CPAP without humidification. 


\section{EfFect of Heated Humidification on CPAP Adherence in OSA}

Either a nasal mask or a full face mask was utilized during the study, based on each subject's preference. All of the machines had recordable stick in which information regarding CPAP adherence, AHI, and leak was able to be downloaded.

\section{Humidity Logger}

A small device, the HOBO UX100 Temp/RH 3.5\% data logger (Onset Computer Corporation, Bourne, Massachusetts) was utilized in the study. This device was designed to record the temperature and humidity of the surroundings. This device can record the temperature from 20 to $70{ }^{\circ} \mathrm{C}$ and the relative humidity from 15 to $95 \%$. It was attached to the side of the CPAP device. The aim was to measure the ambient temperature and humidity level in the subject's bedroom. All of the subjects were instructed to keep their CPAP machine in their bedroom at all times.

\section{Study Design}

In this prospective single blind randomized crossover study, data were collected from the Excellence Center for Sleep Disorders at King Chulalongkorn Memorial Hospital, Thai Red Cross Society, Bangkok, Thailand. Subjects with moderate to severe OSA with nasopharyngeal symptoms during CPAP titration conducted during a split-night study according to a post-test questionnaire were offered participation in the study. Subjects were randomly assigned by bloc sizes of 4 to receive CPAP with or without heated humidification for 4 weeks and then crossed over to receive another treatment for 4 weeks (the subjects were blinded to the treatment arm). All of the subjects received proper education and support on the use of the CPAP device given by the primary investigator before initiation of CPAP. Baseline clinical and polysomnographic characteristics were collected at the initial visit. Follow-up clinical data were collected, including CPAP adherence, AHI, and leak (downloaded from the device), symptoms of excessive daytime sleepiness, quality of life, and adverse effects (obtained from questionnaires) at 4 weeks after the CPAP (with or without heated humidification, depending on randomization). In order to take into an account the period when the subjects were getting accustomed to the use of CPAP (the first week), only the last 3 weeks of data were analyzed. Then the subject was crossed over to use CPAP with humidification using the same machine for another 4 weeks. Then data of the last 3 weeks on CPAP adherence, AHI, and leak (downloaded from the device), symptoms of excessive daytime sleepiness, quality of life, and adverse effects (obtained from questionnaires) were analyzed. Eight-week data of bedroom temperature and relative humidity level measured by the humidity logger were collected at the end of the study ( 8 weeks after the
CPAP was given). The objectives of the study were to determine the effect of heated humidification on adherence, quality of life, and nasopharyngeal adverse effects during CPAP therapy in subjects with OSA with nasopharyngeal symptoms. The primary outcome was average hours of use for all days. Secondary outcomes were average hours of use for the days of use, total days of use, total days of use $>4 \mathrm{~h}, \mathrm{AHI}$, mean system leak, 95th percentile system leak, nasopharyngeal symptoms, symptoms of excessive daytime sleepiness, and quality of life.

\section{Statistical Analysis}

All of the data were first tested for data normality using the Shapiro-Wilk normality test. Data were expressed as mean \pm SD for normally distributed data, and as median (interquartile range) for non-normally distributed data. Baseline characteristics and changes in outcome variables were compared by repeated measurement analysis of variance with 2 factors. Changes in outcome measurements over time in the whole study population were compared by paired $t$ test or signed-rank test. All analyses were undertaken using the intention-to-treat principle. The expected difference in the primary outcome variable (adherence), which might be clinically important, and the pooled SD were specified on the basis of the previously published studies. The required sample size to detect a difference of $1.0 \mathrm{~h}$ with $90 \%$ power and $\alpha=0.05$ was 19 subjects per group. The total number of subjects was planned to be 21 , since we expected a potential dropout rate of $10 \%$.

\section{Results}

A total of 20 subjects with OSA were enrolled in the study during the period of January to December 2014. One-hundred four patients were referred for split-polysomnography and completed the post-test questionnaire. There were 62 subjects who had a nasopharyngeal symptom score of $>2$ (moderate symptom) eligible for enrollment, of which 40 patients were excluded for multiple reasons; 2 more subjects dropped out from the study in the first week after CPAP use, and the reasons for dropout was CPAP refusal. Data were collected on 20 subjects with OSA (Fig. 1). Baseline characteristics demonstrated that most of the subjects were middle-age, male, and obese and experienced excessive daytime sleepiness (Table 1). None of the subjects were using oxygen supplementation. The post-split-night nasopharyngeal symptoms assessed by the modified XERO questionnaire reveal that dry mouth and dry throat/sore throat were among the most common adverse effects (Table 2). Polysomnographic characteristics demonstrated that most of the subjects had severe OSA with moderate to severe oxygen desaturations, borderline poor sleep efficiency, and frequent arousal (Table 3). 


\section{EfFect of Heated Humidification on CPAP AdHEREnce in OSA}

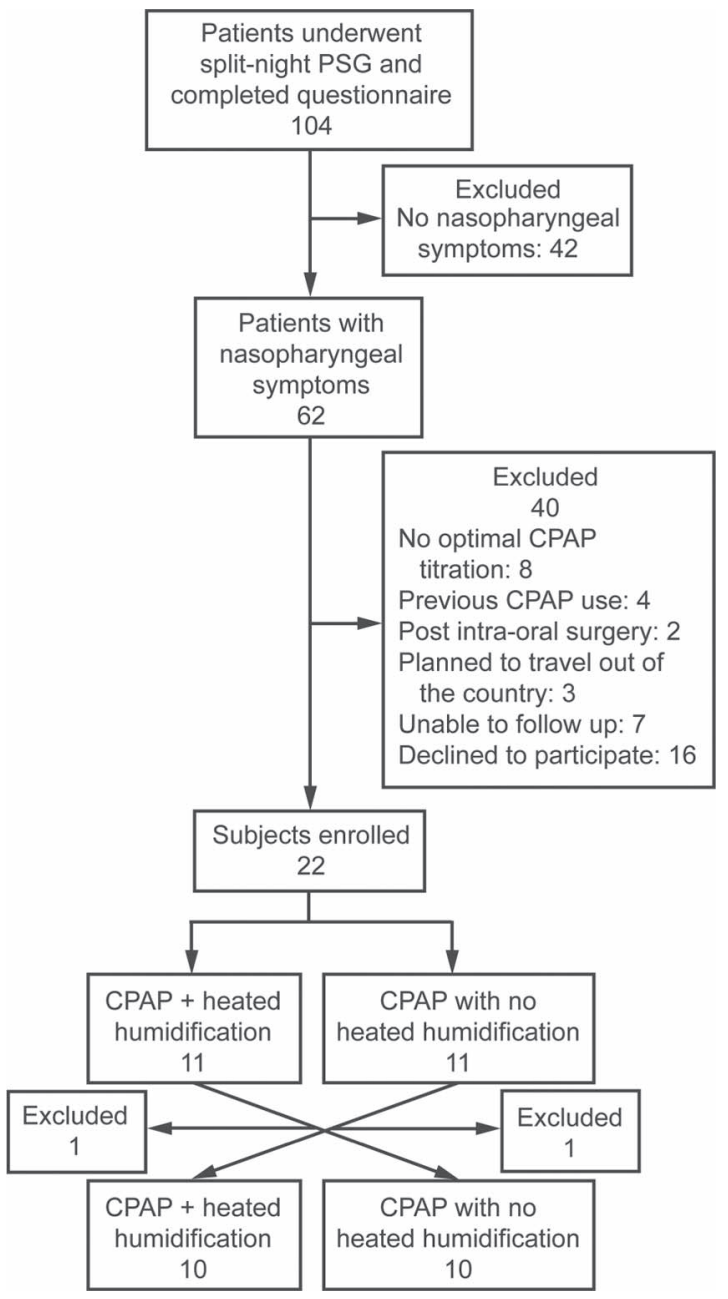

Fig. 1. Flow chart. PSG = polysomnography.

Regarding the use of CPAP, 17 subjects chose to use the nasal mask, and 3 subjects chose to use the full face mask. Although the addition of heated humidification appeared to improve the average hours of use for all days when compared with conventional CPAP, the difference was not statistically significant (CPAP with heated humidification $=4.6 \pm 1.7 \mathrm{~h} / \mathrm{night}$; conventional CPAP $=4.0 \pm 1.7$ $\mathrm{h} /$ night, $P=.10$ ). However, the addition of heated humidification improved CPAP adherence on the days of CPAP use $(5.5 \pm 1.5 \mathrm{~h} /$ night $)$ compared with conventional CPAP (5.2 $\pm 1.4 \mathrm{~h} / \mathrm{night}), P=.033$. Overall, there was a trend toward improvement in CPAP use based on all adherence parameters. The AHI and leak data were not different between the 2 groups (Table 4 ).

Quality of life after 4 weeks measured by the Functional Outcomes of Sleep Questionnaire, when compared with baseline, appeared to be increased significantly in the total Functional Outcomes of Sleep Questionnaire score and vigilance (CPAP therapy with heated humidification) as well as in sexual outcome (both interventions). When a
Table 1. Baseline Clinical Characteristics of All Subjects

\begin{tabular}{|c|c|}
\hline Clinical Characteristics & Values \\
\hline Age, mean $\pm \mathrm{SD}$ y & $48.9 \pm 12.7$ \\
\hline Male sex, $n(\%)$ & $14(70)$ \\
\hline Height, mean $\pm \mathrm{SD} \mathrm{cm}$ & $165.4 \pm 8.9$ \\
\hline Weight, mean \pm SD kg & $76.8 \pm 12.5$ \\
\hline $\mathrm{BMI}$, mean $\pm \mathrm{SD} \mathrm{kg} / \mathrm{m}^{2}$ & $28.1 \pm 4.9$ \\
\hline Neck circumference, mean $\pm \mathrm{SD} \mathrm{cm}$ & $39.6 \pm 3.8$ \\
\hline Waist circumference, mean $\pm \mathrm{SD} \mathrm{cm}$ & $96.2 \pm 10.6$ \\
\hline \multicolumn{2}{|l|}{ Smoking, $n(\%)$} \\
\hline Non-smokers & $14(70)$ \\
\hline Ex-smokers & $1(5)$ \\
\hline Smokers & $5(25)$ \\
\hline \multicolumn{2}{|l|}{ Alcohol, $n(\%)$} \\
\hline No alcohol drinking & $14(70)$ \\
\hline Social drinking & $4(20)$ \\
\hline Regular drinking & $2(10)$ \\
\hline \multicolumn{2}{|l|}{ Underlying disease, $n(\%)$} \\
\hline No underlying disease & $5(25)$ \\
\hline Hypertension & $10(50)$ \\
\hline Ischemic heart disease & $1(5)$ \\
\hline Hyperlipidemia & $5(25)$ \\
\hline Diabetes mellitus & $2(10)$ \\
\hline Allergic rhinitis & $5(25)$ \\
\hline Alzheimer disease & $1(5)$ \\
\hline Fatty liver & $1(5)$ \\
\hline Acromegaly & $1(5)$ \\
\hline Systemic lupus erythematosus & $1(5)$ \\
\hline \multicolumn{2}{|l|}{ Medication, $n(\%)$} \\
\hline Antihypertensive drug & $6(30)$ \\
\hline Antipsychotic drug & $0(0)$ \\
\hline Antidepressant drug & $0(0)$ \\
\hline Benzodiazepine & $2(10)$ \\
\hline Benign prostatic hypertrophy drug ( $\alpha$ blocker drug) & $1(5)$ \\
\hline
\end{tabular}

comparison was made between the 2 interventions, there was an improvement in quality of life based on Functional Outcomes of Sleep Questionnaire score with CPAP therapy with heated humidification (median 17.6 [IQR 3.5]) compared with conventional CPAP (median 17.6 [IQR $4.5]), P=.046$. The Epworth Sleepiness Scale score was not different when compared between the 2 interventions (Table 5).

Four weeks after CPAP therapy with heated humidification, the overall total nasopharyngeal symptom score did not differ from CPAP without heated humidification (median 5 [IQR 5.5] vs 6 [IQR 5.5], $P=.19$ ). However, the dry throat/sore throat symptom was improved with the use of heated humidification compared with CPAP without heated humidification (median 1 [IQR 1.5] vs 2 [IQR 1.5], $P<.001$ ) (Table 6). Only 2 subjects complained of wetness during the use of CPAP therapy with heated humidification. The analysis comparing the group with 


\section{EFFect of Heated Humidification on CPAP AdHERENCE IN OSA}

Table 2. Baseline Nasopharyngeal Symptom Score Assessed by Modified XERO Questionnaire Post-Split-Night Polysomnography of All Subjects

\begin{tabular}{lc}
\hline \hline Nasopharyngeal Symptoms & Score \\
\hline Total score & $6.8 \pm 3.8$ \\
Blocked nose & $1.3 \pm 1.0$ \\
Dry nose & $0.9 \pm 0.9$ \\
Runny nose & $0.3 \pm 0.6$ \\
Dry mouth & $1.9 \pm 1.1$ \\
Dry throat/sore throat & $1.9 \pm 1.1$ \\
Itchy eyes & $0.5 \pm 0.8$ \\
Watery eyes & $0.2 \pm 0.5$ \\
\hline Data are mean \pm SD. & \\
\hline
\end{tabular}

Table 3. Baseline Polysomnographic Characteristics of All Subjects

\begin{tabular}{ll}
\hline \hline Polysomnographic Characteristics & \multicolumn{1}{c}{ Values } \\
\hline AHI, events/h & $53.7 \pm 21.9$ \\
RDI, events/h & $54.4 \pm 22.0$ \\
Mean $\mathrm{S}_{\mathrm{pO}_{2}}, \%$ & $91.9 \pm 3.5$ \\
Nadir $\mathrm{pO}_{2}, \%$ & $74.8 \pm 10.5$ \\
Time spent with $\mathrm{S}_{\mathrm{pO}_{2}}<90 \%, \%$ & $11.1 \pm 10.0$ \\
Arousal index, events/h & $43.6 \pm 23.1$ \\
Sleep efficiency, $\%$ & $83.0 \pm 11.7$ \\
NREM1, $\%$ & $17.3 \pm 13.8$ \\
NREM2, \% & $51.3 \pm 18.4$ \\
NREM3, \% & $20.4 \pm 15.7$ \\
REM, $\%$ & $11.0 \pm 9.4$ \\
CPAP, cm $\mathrm{H}_{2} \mathrm{O}$ & $10.5 \pm 3.6$
\end{tabular}

Data are mean \pm SD.

$\mathrm{AHI}=$ apnea-hypopnea index

$\mathrm{RDI}=$ respiratory disturbance index

NREM1 $=$ non-rapid eye movement 1

NREM2 $=$ non-rapid eye movement 2

NREM3 $=$ non-rapid eye movement 3

$\mathrm{REM}=$ rapid eye movement

benefit from heated humidification with the group without showed that the total score of the modified XERO questionnaire addressing the nasopharygeal symptoms was statistically significantly higher in the group benefiting from heated humidification. No other factors, including clinical characteristics, comorbidities, polysomnographic characteristics, type of medication use, baseline Epworth Sleepiness Scale score, baseline Functional Outcomes of Sleep Questionnaire score, type of CPAP mask, or CPAP pressure, were associated with improvement in CPAP adherence with the use of heated humidification. The analysis also revealed that when there was an increase in one point of dry throat/sore throat score, adherence was shown to increase by approximately $0.5 \mathrm{~h}$. The ambient temperature and relative humidity level were similar during the use of CPAP
Table 4. Downloaded Data From CPAP With and Without Heated Humidification

\begin{tabular}{|c|c|c|c|}
\hline CPAP Parameters & $\begin{array}{l}\text { CPAP With Heated } \\
\text { Humidification }\end{array}$ & $\begin{array}{l}\text { CPAP Without } \\
\text { Heated } \\
\text { Humidification }\end{array}$ & $P$ \\
\hline $\begin{array}{l}\text { Total days of use, median } \\
\text { (IQR) d }\end{array}$ & $18.5(3.5)$ & $17(7.5)$ & .09 \\
\hline $\begin{array}{c}\text { Average hours of use for all } \\
\text { days, mean } \pm \mathrm{SD} \text { h/night }\end{array}$ & $4.6 \pm 1.7$ & $4.0 \pm 1.7$ & .10 \\
\hline $\begin{array}{l}\text { Average hours of use for } \\
\text { the days of use, } \\
\text { mean } \pm \mathrm{SD} \text { h/night }\end{array}$ & $5.5 \pm 1.5$ & $5.2 \pm 1.4$ & .033 \\
\hline $\begin{array}{l}\text { Total days of use }>4 \mathrm{~h}, \\
\text { median (IQR) d }\end{array}$ & $16.5(9.5)$ & $14.0(10)$ & .22 \\
\hline AHI, median (IQR) events/h & $4.5(4)$ & $4.2(4.1)$ & .17 \\
\hline $\begin{array}{l}\text { Mean system leak, } \\
\text { mean } \pm \mathrm{SD} \mathrm{L} / \mathrm{min}\end{array}$ & $31.9 \pm 7.6$ & $32.4 \pm 9.7$ & .61 \\
\hline $\begin{array}{l}\text { 90th percentile system leak, } \\
\text { median (IQR) L/min }\end{array}$ & $44.5(12)$ & $44.5(20)$ & .78 \\
\hline
\end{tabular}

with heated humidification and CPAP without heated humidification (Table 7).

\section{Discussion}

To our knowledge, our study is the first study conducted in a tropical climate area on the effect of heated humidification on CPAP adherence in OSA treatment in subjects with moderate to severe OSA with nasopharyngeal symptoms after CPAP titration. When a comparison was made between the use of CPAP with heated humidification and CPAP without heated humidification, we demonstrated improvement in adherence with the addition of heated humidification. For our primary objective, which was average hours of use for all days, the addition of heated humidification appeared to improve CPAP adherence; however, the difference was not statistically significant. On the other hand, the average hours of use on the days of use was statistically significantly improved when heated humidification was employed. The average hours of use on the days of use may be deemed important because it has been recommended as a parameter to be monitored for CPAP adherence. ${ }^{16} \mathrm{We}$ also demonstrated, along with the improvement in adherence, an improvement in quality of life. In contrast, previous studies ${ }^{7-9}$ did not achieve the same result. Ryan et al ${ }^{7}$ conducted a study comparing the 4-week use of dry CPAP, CPAP with heated humidification, and CPAP with additional topical nasal steroid application in 125 subjects with the established diagnosis of OSA (AHI $\geq 10$ events/h). This study demonstrated that CPAP with heated humidification improved frequency of nasal symptoms; however, adherence and quality of life remained 


\section{EfFect of Heated Humidification on CPAP AdHERENCE in OSA}

Table 5. Epworth Sleepiness Scale Score and Functional Outcomes of Sleep Questionnaire Score Comparing the Baseline, the Use of CPAP With Heated Humidification, and CPAP Without Heated Humidification

\begin{tabular}{|c|c|c|c|c|c|c|}
\hline Questionnaire & Baseline & $\begin{array}{l}\text { CPAP With Heated } \\
\text { Humidification }\end{array}$ & $P^{*}$ & $\begin{array}{l}\text { CPAP Without Heated } \\
\text { Humidification }\end{array}$ & $P \dagger$ & $P \ddagger$ \\
\hline Total ESS score, mean \pm SD & $11.5 \pm 5.0$ & $9.6 \pm 4.1$ & .10 & $9.6 \pm 4.2$ & .14 & .86 \\
\hline Total FOSQ score, median (IQR) & $17.0(5.6)$ & $17.6(3.5)$ & .02 & $17.6(4.5)$ & .21 & .046 \\
\hline Activity level, mean $\pm \mathrm{SD}$ & $3.0 \pm 0.7$ & $3.3 \pm 0.5$ & .063 & $3.3 \pm 0.6$ & .13 & .72 \\
\hline General producibility, median (IQR) & $3.4(0.7)$ & $3.5(1.0)$ & .57 & $3.5(1.1)$ & .69 & .062 \\
\hline Social outcome, median (IQR) & $3.8(1.3)$ & $4(1)$ & .31 & $3.5(1.6)$ & $>.99$ & .19 \\
\hline Vigilance, median (IQR) & $3.0(0.9)$ & $3.3(0.8)$ & .034 & $3.3(0.8)$ & .14 & .65 \\
\hline Sexual activity outcome, median (IQR) & $3.3(1.4)$ & $4(0.6)$ & .02 & $4(0.5)$ & .03 & .57 \\
\hline \multicolumn{7}{|c|}{$\begin{array}{l}\text { * Baseline vs CPAP with heated humidification. } \\
\dagger \text { Baseline vs CPAP without heated humidification. } \\
¥ \text { CPAP with heated humidification vs CPAP without heated humidification. } \\
\text { IQR = interquartile range } \\
\text { ESS = Epworth sleepinee scale } \\
\text { FOSO = functional outcome of }\end{array}$} \\
\hline
\end{tabular}

Table 6. Nasopharyngeal Symptom Score Assessed by Modified XERO Questionnaire With the Use of CPAP With and Without Heated Humidification

\begin{tabular}{lccc}
\hline \hline $\begin{array}{l}\text { Nasopharyngeal } \\
\text { Symptom Score }\end{array}$ & $\begin{array}{c}\text { CPAP With Heated } \\
\text { Humidification }\end{array}$ & $\begin{array}{c}\text { CPAP Without Heated } \\
\text { Humidification }\end{array}$ & $P$ \\
\hline Total score & $5(5.5)$ & $6(5.5)$ & .19 \\
Blocked nose & $1(1)$ & $1(1.5)$ & .12 \\
Dry nose & $1(1)$ & $1(2)$ & $>.99$ \\
Runny nose & $0(1)$ & $0(1)$ & .87 \\
Dry mouth & $1(1.5)$ & $1(2)$ & .62 \\
Dry throat/sore & $1(1.5)$ & $2(1.5)$ & $<.001$ \\
$\quad$ throat & $0(0.5)$ & $0(1)$ & .55 \\
Itchy eyes & $0(0)$ & $0(0.5)$ & .062 \\
Watery eyes & & &
\end{tabular}

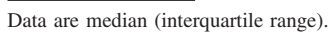

Table 7. Ambient Relative Humidity With the Use of CPAP With and Without Heated Humidification

\begin{tabular}{lccc}
\hline \hline $\begin{array}{c}\text { Temperature and } \\
\text { Humidity }\end{array}$ & $\begin{array}{c}\text { CPAP With Heated } \\
\text { Humidification }\end{array}$ & $\begin{array}{c}\text { CPAP Without Heated } \\
\text { Humidification }\end{array}$ & $P$ \\
\hline Room temperature, ${ }^{\circ} \mathrm{C}$ & $28.8 \pm 1.9$ & $28.6 \pm 1.9$ & .23 \\
Relative humidity, \% & $62.9 \pm 4.6$ & $63.2 \pm 3.1$ & .84
\end{tabular}

Data are mean $\pm \mathrm{SD}$

unchanged. ${ }^{7}$ Another study by Ruhle et al, ${ }^{8}$ which was a 4-week crossover study comparing the use of conventional CPAP with CPAP with heated humidification on 44 subjects with OSA, also only demonstrated the positive effect on dryness of the mouth. However, adherence and quality of life were not altered. ${ }^{8}$ Routine use of heated humidification with CPAP was once again shown to have no effect on adherence according to the study conducted by Worsnop et al $^{9}$ This study was a randomized, parallel group design comparing 3 months of use of conventional CPAP and CPAP with heated humidification. The study demonstrated improvement in the symptoms of blocked nose, sneezing, dry nose, stuffy nose, dry mouth, and runny nose. However, adherence was similar between the 2 groups. We believe that the main reasons why our study's results differ from those of other studies were the subjects' selection and the timing to utilize the heated humidification. Our study selected a group of subjects with OSA who experienced problems with nasal-oral adverse effects during the first night of a CPAP trial. Prior studies have shown that the most common reason for not initiating CPAP is general displeasure or discomfort with the CPAP device during the CPAP titration trial ${ }^{17}$ or during the first night of therapy. ${ }^{2}$ We aimed to improve the symptoms related to CPAP early in this group rather than waiting for nasopharyngeal symptoms to occur later after the use of CPAP. We proved that this intervention can improve adherence on the days of CPAP use as well as quality of life. In our study, a nasal mask was the primary mask utilized. According to the clinical guidelines for the evaluation, management and long-term care of obstructive sleep apnea in adults, a nasal mask is the preferred delivery route, since previous studies have demonstrated that a full face mask may be associated with lower CPAP adherence. ${ }^{14,18}$

We also demonstrated that nasopharyngeal symptoms were better with the addition of heated humidification, particularly for dry/sore throat. Dry throat/sore throat is a known frequent complaint of the subjects using CPAP. Prior studies 6,19 have shown that nasal CPAP devices cause dryness of inspired air from reduction of relative humidity, resulting in dry throat and sore throat, which can be improved with addition of heated humidification. We believed that dry throat/sore throat observed in our study was 


\section{EfFect of Heated Humidification on CPAP Adherence in OSA}

mostly related to the use of CPAP and was improved with implementation of heated humidification, leading to better CPAP adherence. The lack of improvement in the dry nose symptom despite improvement in the dry throat/sore throat symptom may be related to the small sample size. A prior study ${ }^{3}$ has shown that a heated humidifier can compensate for the dehydration effects induced by CPAP therapy with nasal mask leak by increasing the absolute humidity level. Mouth leak, another common problem when a nasal mask was utilized, can increase nasal mucosal blood flow, which causes a large increase in nasal resistance. Our study did not demonstrate significant nasal mask leak or mouth leak, since system leak values were within the acceptable range. We can postulate that the greater benefit of adding heated humidification to CPAP would be expected if there had been a significant leak. A prior report ${ }^{20}$ demonstrated that adding heated humidification may reduce nasal peak inspiratory flow, which may contribute to increasing CPAP adherence in subjects with obstructive sleep apnea with concomitant allergic rhinitis. We demonstrated that approximately $25 \%$ of our subjects had a history of allergic rhinitis. However, an otolaryngology examination was not performed to confirm the diagnosis in our study.

Regarding the humidity data, our humidity logger reported average relative humidity in the subjects' bedroom of $62 \%$. All of our subjects resided in Bangkok or a neighboring province with reported outdoor relative humidity over the year of approximately $80 \%$ (according to World Weather \& Climate Information, www.weather-andclimate.com. Accessed January 22, 2016). This substantially lower average relative humidity was mostly explained by the effect of air conditioners. Seventy percent of the subjects in this study disclosed that they slept nightly with air conditioning. An air conditioner is known to lower the relative humidity, partly because when the air passes through the air conditioner, some mass of the water vapor will be condensed. Although the relative humidity will be at $100 \%$, the actual amount of water vapor will be very much reduced. Therefore, the air leaving the air conditioner will have lower relative humidity. ${ }^{21}$ This action of the air conditioner most likely explains the lower relatively humidity observed in our study despite the study being conducted in a tropical climate area. However, this relative humidity appeared to have no effect on CPAP adherence, since there was no difference in the relative humidity level during the use of CPAP with heated humidification and during the use of CPAP without heated humidification.

Despite our study demonstrating important positive findings, we are aware that our study carries some limitations besides a relatively small sample size. First, although the subjects were blinded to the treatment by using the CPAP with built-in humidification as well as being instructed to refill the water nightly before each use, they may still have noticed a difference in terms of the temperature of the inspired air delivered by the CPAP as well as the amount of water evaporated from the humidification chamber. Second, our study was conducted in an urban area in which most of the subjects slept with an air conditioner, which lowered the relative humidity, as mentioned earlier. The findings of our study may not be applicable to the general population in tropical climate areas. Also, the relative humidity that was measured in our study was the ambient relative humidity, not the actual relative humidity of the inspired air. Nasal CPAP itself could have lowered the inspired air temperature, which was not measured in our study as well. Third, the improvement in adherence of approximately 20 min observed with the use of CPAP with heated humidification may not have clinical importance. However, this improvement may be substantial when compared with autotitrating CPAP, which provides only an additional 11 min compared with conventional fixed-pressure CPAP. ${ }^{22}$ Autotitrating CPAP also generally yields a more expensive cost compared with adding heated humidification; in particular, some newer CPAP devices have built-in heated humidification with a cost comparable with that of conventional CPAP. Because our study lasted for only 4 weeks, a study with a longer duration is needed to confirm the clinical benefit and cost-effectiveness of adding heated humidification to CPAP in OSA treatment.

\section{Conclusions}

Even in a tropical climate area, CPAP adherence and quality of life were improved when heated humidification was employed in subjects with moderate to severe OSA with nasopharyngeal symptoms post-split-night polysomnography. The improvement may be related to a reduction in dry throat/sore throat symptom.

\section{REFERENCES}

1. Kushida CA, Littner MR, Hirshkowitz M, Morgenthaler TI, Alessi CA, Bailey D, et al. Practice parameters for the use of continuous and bilevel positive airway pressure devices to treat adult patients with sleep-related breathing disorders. Sleep 2006;29(3):375-380.

2. Russell T. Enhancing adherence to positive airway pressure therapy for sleep disordered breathing. Semin Respir Crit Care Med 2014; 35(5):604-612.

3. Fischer Y, Keck T, Leiacker R, Rozsasi A, Rettinger G, Gruen PM. Effects of nasal mask leak and heated humidification on nasal mucosa in the therapy with nasal continuous positive airway pressure (nCPAP). Sleep Breath 2008;12(4):353-357.

4. Mador MJ, Krauza M, Pervez A, Pierce D, Braun M. Effect of heated humidification on compliance and quality of life in patients with sleep apnea using nasal continuous positive airway pressure. Chest 2005;128(4):2151-2158.

5. Rakotonanahary D, Pelletier-Fleury N, Gagnadoux F, Fleury B. Predictive factors for the need for additional humidification during nasal continuous positive airway pressure therapy. Chest 2001;119(2):460465 . 


\section{EfFect of Heated Humidification on CPAP Adherence in OSA}

6. Massie CA, Hart RW, Peralez K, Richards GN. Effects of humidification on nasal symptoms and compliance in sleep apnea patients using continuous positive airway pressure. Chest 1999;116(2):403-408.

7. Ryan S, Doherty LS, Nolan GM, McNicholas WT. Effects of heated humidification and topical steroids on compliance, nasal symptoms, and quality of life in patients with obstructive sleep apnea syndrome using nasal continuous positive airway pressure. J Clin Sleep Med 2009;5(5):422-427.

8. Ruhle KH, Franke KJ, Domanski U, Nilius G. Quality of life, compliance, sleep and nasopharyngeal side effects during CPAP therapy with and without controlled heated humidification. Sleep Breath 2011; 15(3):479-485.

9. Worsnop CJ, Miseski S, Rochford PD. Routine use of humidification with nasal continuous positive airway pressure. Intern Med J 2010; 40(9):650-656.

10. Fox PC, Busch KA, Baum BJ. Subjective reports of xerostomia and objective measures of salivary gland performance. J Am Dent Assoc 1987;115(4):581-584.

11. Banhiran W, Assanasen P, Metheetrairut C, Nopmaneejumruslers C, Chotinaiwattarakul W, Kerdnoppakhun J. Functional outcomes of sleep in Thai patients with obstructive sleep-disordered breathing. Sleep Breath 2012;16(3):663-675.

12. Banhiran W, Assanasen $P$, Nopmaneejumruslers $C$, Metheetrairut $C$. Epworth sleepiness scale in obstructive sleep disordered breathing: the reliability and validity of the Thai version. Sleep Breath 2011; 15(3):571-577.

13. Iber C, Ancoli-Israel S, Chesson A, Quan SF. The AASM manual for the scoring of sleep and associated events: rules, terminology, and technical specifications, 1st edition. Westchester, Illinois: American Academy of Sleep Medicine; 2007.

14. Epstein LJ, Kristo D, Strollo PJ Jr., Friedman N, Malhotra A, Patil $\mathrm{SP}$, et al. Clinical guideline for the evaluation, management and long-term care of obstructive sleep apnea in adults. J Clin Sleep Med 2009;5(3):263-276.

15. Kushida CA, Chediak A, Berry RB, Brown LK, Gozal D, Iber C, et al. Clinical guidelines for the manual titration of positive airway pressure in patients with obstructive sleep apnea. J Clin Sleep Med 2008;4(2):157-171

16. Gay P, Weaver T, Loube D, Iber C. Evaluation of positive airway pressure treatment for sleep related breathing disorders in adults. Sleep 2006;29(3):381-401.

17. Wolkove N, Baltzan M, Kamel H, Dabrusin R, Palayew M. Longterm compliance with continuous positive airway pressure in patients with obstructive sleep apnea. Can Respir J 2008;15(7):365-369.

18. Andrade RG, Piccin VS, Nascimento JA, Viana FM, Genta PR, Lorenzi-Filho G. Impact of the type of mask on the effectiveness of and adherence to continuous positive airway pressure treatment for obstructive sleep apnea. J Bras Pneumol 2014;40(6):658-668.

19. De Araújo MTM, Vieira SB, Vasquez EC, Fleury B. Heated humidification or face mask to prevent upper airway dryness during continuous positive pressure therapy. Chest 2000;117(1):142-147.

20. Winck JC, Delgado JL, Almeida JM, Marques JA. Heated humidification during nasal continuous positive airway pressure for obstructive sleep apnea syndrome: objective evaluation of efficacy with nasal peak inspiratory flow measurements. Am J Rhinol 2002;16(3): 175-177.

21. Talbott J, Hanley AJ, eds. ASHRAE Standard Addendum to Thermal Environmental Conditions for Human Occupancy. Atlanta: American Society of Heating, Refrigerating, and Air-Conditioning Engineers, 1995.

22. Ip S, D'Ambrosio C, Patel K, Obadan N, Kitsios GD, Chung M, Balk EM. Auto-titrating versus fixed continuous positive airway pressure for the treatment of obstructive sleep apnea: a systematic review with meta-analyses. Syst Rev 2012;1:20.

This article is approved for Continuing Respiratory Care Education credit. For information and to obtain your CRCE

(free to AARC members) visit www.rcjournal.com

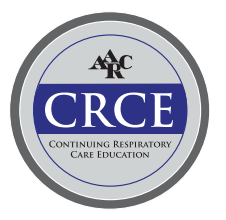

